\title{
ARTE COMO TEOLOGÍA. INTRODUCCIÓN A LA PERSPECTIVA ICONOLÓGICA Y LA ESTÉTICA BIZANTINAS
}

\author{
Agustín Garcells
}

Fecha de recepción: 08/2016

Fecha de aceptación: 09/2016

\begin{abstract}
Resumen:
El discurso estético bizantino se encuentra firmemente relacionado con el dogma teológico, particularmente el cristológico. El objetivo del presente estudio es resaltar la importancia de este discurso, partiendo del hecho de que se corresponde con una experiencia artística todavía vigente. Este ensayo pretende relacionar los elementos de la teología del icono bizantino, en la medida en que esta se articula dentro de la tradición oriental y con las definiciones de arte de algunos pensadores orientales y occidentales más contemporáneos. Estas definiciones consideran a la obra de arte más que una forma de objetivación cultural, como un modo de conocimiento de la "verdad". El estudio da por sentado que, en lo que respecta al arte cristiano, la "verdad", más que un concepto filosófico o una operación intelectual, constituye una persona específica: la persona de Cristo, el "Theánthropos".
\end{abstract}

Palabras clave: icono, bizantino, arte, estética, cristianismo.

\begin{abstract}
:
Byzantine aesthetic discourse is firmly related to the theological dogma, specifically the Christological one. This study highlights the meaning of this debate, based on the fact that it relates to a still existing artistic experience. This essay tries to connect the elements of theology on Byzantine icons, with eastern tradition and meanings of art in contemporary eastern and western thinkers. These definitions favor the work of art, rather than a form of cultural objectification, as a way of realizing the "truth". It is assumed that respect to Christian art as well as the "truth" rather than a philosophical concept or intellectual operation, establishes a specific person: the person of Christ, the "Theanthropos".
\end{abstract}

Key words: icon, byzantine, art, aesthetic, Christianism.

\begin{abstract}
Autor:
M.Sc. Agustín Garcells Suárez. Cuba, 1979. Licenciado en Historia del Arte por la Universidad de La Habana, Cuba (2003). Licenciado (2011), Máster (M.Sc.) (2012) y Candidato a Doctor en Teología (2012-2018) por la Universidad Aristotélica de Tesalónica, Grecia. Es profesor de Historia del Arte y Estética en la Carrera de Artes Visuales de la Pontificia Universidad Católica del Ecuador en Quito.
\end{abstract}


"Los iconos nacen del arte y deben permanecer en el ámbito del arte. Si bien fundado y desarrollado dentro de la tradición, el icono tiene su propia vida y su lugar en el arte moderno”.

Sergei Bulgakov (1988, 143)

El cristianismo originario, en concordancia con el mandamiento bíblico y como consecuencia también de las persecuciones de las autoridades romanas, no concibe ninguna forma de "arte"

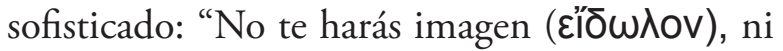
ninguna semejanza de cosa que esté arriba en el cielo, ni abajo en la tierra, ni en las aguas debajo de la tierra. No te inclinarás ( $\pi \rho 0 \sigma \kappa v v \eta ́ \sigma \varepsilon เ \varsigma)$

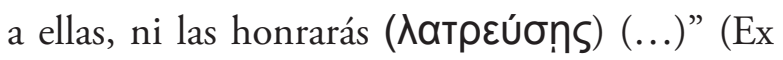
20:4-5). Destacan representaciones elementales y contingentes de tipo místico-expresivo, a las que el teólogo Pavel Evdokimov (1901-1970) denomina "signos". Para el pensador ruso, los orígenes del arte cristiano (alrededor del siglo IV d. C.) estriban en la dialéctica que se establece entre "signo" y "símbolo" (1982: 133-139). El "signo" _ la representación del Buen Pastor, el acróstico del Pez, el anagrama o Crismón, el ancla- no solo constituye una forma de "encriptar" o "codificar" la doctrina religiosa, sino que tiene exclusivamente una función didáctica. Por otro lado, el "símbolo" aquí constituye la forma superior del arte religioso o eik $\omega \dot{v}$ /eikón, esto es "icono", "imagen", que se caracteriza por la presencia simbólica del prototipo o la relación más directa con este prototipo, y por consiguiente la realización del culto religioso o litúrgico a través de esta imagen ${ }^{2}$.

Esta concepción, desarrollada con el paso del tiempo, enfrentaría hacia los siglos VIII y IX d. C., una violenta persecución, conocida como "Iconoclasia" o "Iconomaquia". El movimiento iconoclasta enarbolaba dos argumentos en contra de la iconografía religiosa: la absoluta trascendencia de Dios y la prohibición bíblica de representarlo. A pesar de todo, para el Séptimo Concilio Ecuménico (787 d. C.), se reconoce oficialmente la veneración de los iconos, una decisión sinodal que sería nuevamente revocada por los iconoclastas, trayendo consigo el martirio de muchos cristianos. Dentro de este cuadro sangriento, vería la luz una de las teorías estéticas más trascendentales para la historia del arte. ${ }^{3}$

El primer Padre de la Iglesia que trata sistemáticamente con el arte religioso fue san Juan Damasceno (675-749 d. C.). Anteriormente, sobresalen también los puntos de vista todavía tímidos de san Basilio Magno (330-379 d. C.) y san Gregorio Magno (540-604 d. C.). El primero escribe: “(...) porque aquello que el logos de la historia representa a través del sonido, también la imagen silenciosa mostrará por medio de la imitación" (Basilio Magno, PG, 31: 484-489). ${ }^{4}$ Por su parte, Gregorio añade: “(...) la pintura puede ser para los iletrados lo mismo que la escritura para los que saben leer" (Gombrich, 2011: 105). Sin embargo, ambos casos se limitan todavía a exaltar el carácter didáctico o "sígnico" del arte iconográfico. Algo que no debe subestimarse, teniendo en cuenta que la finalidad pedagógica parece inherente también a toda práctica artística, pero en el caso de la iconografía bizantina, constataremos que se trata de una experiencia de índole incluso mucho más radical.

La definición del arte de san Juan Damasceno aparece formulada en el texto $A$ los que calumnian los Santos Iconos (PG, 94: 1231) y estaría basada esencialmente en la teología de la Encarnación del Logos de Dios, el fundamento o dogma más importante de la doctrina cristiana. En el texto mencionado, se formulan al respecto cuatro argumentos en defensa de la representación iconográfica: 
1) El argumento bíblico, que se fundamenta en el Antiguo Testamento a pesar de que se trata de un texto que se "expresa tan antropomórficamente acerca de Dios" (Kaimakis, 2007: 17). Por su parte, la autoridad hebrea bastó para que en el terreno de las artes visuales, hasta hoy día, no pueda constatarse una tradición iconográfica antropomórfica, al menos en el Medio Oriente. Sin embargo, resulta paradójico que el desarrollo de un rico imaginario literario, tanto hebreo como islámico, no fuese impedido.

Obviamente, los hebreos no distinguen en el objeto artístico ni su carácter "simbólico", ni "alegórico". Esto es, de la palabra $\sigma v \mu \beta \alpha ́ \alpha \lambda \lambda \omega /$ symbálo, "reunir”, “juntar” con el prototipo,

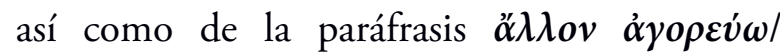
állon agorévo, "hablar (en público) de otra cosa". Es por esto que en ausencia de estos dos constituyentes, la obra de arte pierde su carácter referencial y se identifica completamente con el ente representado. Por consiguiente, cualquier representación de Dios, y específicamente la artística, más allá de su carácter simbólico o alegórico5, constituye una "cosificación" o "realización” del propio Dios como ente trascendente y, por tanto, en la medida que se le rinde "veneración" o "adoración" como si se tratase de un "objeto común" o "mera cosa" (Heidegger, 1992: 41-88) ${ }^{6}$, consiste también en idolatría.

Para los hebreos existe una diferencia radical, formal y conceptual, que establece una jerarquía entre la literatura y las artes visuales, análoga pudiera decirse, al criterio helénico existente ya desde la época clásica. No obstante, esta diferenciación adolece de la capacidad filosófica del pensamiento griego helenístico y es por ello que no le permite relacionar ambos tipos de producción artística. Por otro lado, resulta paradójico que en el antiguo Israel existieran, pese a todo, objetos votivos como el Arca de la Alianza, los cuales se comportan cual si se trataran de una representación abstracta de lo divino, como consecuencia de su carácter "referencial", del principio de la “referencialidad" (Yfantis, 2010: 194). Esto es, que la obra de arte no consiste en un fin en sí misma, sino siempre en virtud de su objeto o sujeto referencial, arquetipo o prototipo, como veremos más adelante.

2) El argumento Cristológico, que se basa en la doctrina de la Encarnación del Logos. Para los cristianos, la "verdad" consiste en la segunda persona de la Trinidad, una entidad con determinado e irrepetible modo de existencia, que resulta de la unión de las naturalezas divina y humana en la persona de Cristo. En este marco, el concepto de "verdad" cristiano resulta análogo también a la definición helénica de la "verdad". Tal y como sería abordado por el filósofo Martin Heidegger (1889-1976) más de un milenio después, aquí la palabra "verdad", del griego $\dot{\alpha} \lambda \dot{\eta} \theta \varepsilon \iota \alpha / a l i ́ t h e i a$, designa una experiencia de "des-ocultamiento" del ente en cuanto ente (1992: 63). En este contexto cristiano, dado que el "Theánthropos" constituye la medida de cada ontología, la "verdad" constituye el ente que se muestra como Cristo o participa de él. Aquí el "arte" resulta ser un modo de comprensión ontológica de lo "ente", es decir de la "verdad" misma. En fin, que dentro del pensamiento cristiano bizantino y meta-bizantino, la "obra de arte" es un "símbolo" de la persona de Cristo, esto es, una teología de la Encarnación o Humanización.

En este sentido, parece natural que la "reforma" iconomáquica fuera considerada en reversa por los iconófilos como herejía, es decir como negación de la "humanización" 
o “encarnación” del Logos. Para la tradición iconófila, "dogmática" por excelencia, lo "cósico" " del ente que constituye la obra de arte, el icono mismo en su dimensión más objetiva, resulta una analogía de la naturaleza humana de Cristo:

¿O no es materia, antes que todo esto, el cuerpo y la sangre de mi Señor? O derogas entonces el respeto y la veneración de todo esto o sométete a la tradición eclesiástica y a la veneración de las imágenes de Dios y de sus amigos, los cuales son santificados en su nombre y por causa de esto revestidos de la gracia del divino Espíritu. (PG, 94: 1245 C)

Por otra parte, gracias a su carácter "simbólico" y "alegórico", el icono representa también la naturaleza divina de Cristo. Sin embargo, esto no resulta evidente en la obra de Damasceno. Respecto a este tema, Giorgios Florovsky (1893-1979) completa:

Dios puede ser representado en el sentido correcto solo por causa de la Encarnación, pero la forma del Encarnado es la forma de Dios, y no solo la forma de un cuerpo. San Juan Damasceno no desarrolla esta idea con detalle, sin embargo, esta emana de sus presupuestos cristológicos generales". (2007: 447)

3) $\mathrm{El}$ argumento votivo, donde el Damasceno analiza el término "veneración" bajo una perspectiva teológica y filosófica en relación al significado litúrgico y la utilidad o función del icono. Según Juan Damasceno, solamente lo in-creado puede ser "adorado", es decir el Dios Trino. En el caso de Cristo, por cuanto en él resulta imposible discernir entre las dos naturalezas, la actitud de "adoración" se mantiene. Por el contrario, la "veneración" e "idolatría" son demostraciones de culto a lo creado. En caso de "idolatría", el ente creado es asumido con las mismas particularidades del ente in-creado, mientras que por "veneración" se entiende el acto de honrar lo creado en virtud de su relación con lo in-creado según participación (Juan Damasceno, PG, 94: 1236 ABC), o lo que es lo mismo, simbólica y alegóricamente, siguiendo la acepción dada anteriormente:

Un solo Dios venero, una divinidad, pero también adoro tres hipóstasis, Dios Padre, Dios Hijo Encarnado y Dios Espíritu Santo, un solo Dios. No venero la creación en lugar del Creador, sino que venero al Creador (es decir, Cristo) que fue creado según la naturaleza humana y descendió a la creación sin verse rebajado, ni alterado, para glorificar mi propia naturaleza y permitirme comulgar con la naturaleza divina”. (PG, 94: 1236 B)

Este argumento abarca también la postura del sujeto espectador, el ser humano, el único ente capaz de experimentar la "verdad". En su actitud reside la esencia de la teología de la imagen, por cuanto el meollo no se encuentra en el objeto creado en cuanto tal, sino en la manera en que se experimenta este ente, en virtud de su participación en el "según naturaleza venerable (adorable) Dios". (Juan Damasceno, PG, 1244 B)

La participación del ente en lo increado, esta apreciación o experiencia, constituye exclusivamente una hipótesis humana, es decir depende de la actitud del "hombre espiritual" (Yfantis, 2010: 194) en relación al objeto votivo y la actividad creativa del artista. Por otro lado, la "referencialidad" del ente no es otra cosa que el carácter simbólico-alegórico de la obra de arte, del objeto religioso también.

4) El último argumento es filosófico, de procedencia helénica y se trata de la célebre 
"teología de la presencia”, basada en el modelo griego "arquetipo-tipo", "prototipo-tipo", de origen platónico. De acuerdo con la concepción platónica, cada forma sensible se corresponde con un arquetipo o prototipo ideal. En el caso del Cristianismo, el ente creado preexiste ya, "preeternamente" en la Mente Divina, entendido como "logos demiúrgico" (Matsoukas, 2010: 156). Aquello que ha sido creado por Dios se corresponde también con determinado arquetipo ideal, teniendo en cuenta que, según la doctrina cristiana, la naturaleza se encuentra en estado de caída o desequilibrio: "La imagen es una semejanza que trae consigo las características del prototipo con determinada diferencia respecto a él" (Juan Damasceno, PG, 94: 1240 C). Elemento que viene a confirmar por último, que existe una conexión directa entre el helenismo clásico y el cristianismo helenístico posterior, cuestión que se vería reiterada de una forma u otra por el resto de los autores citados en el presente ensayo.

Otro de los aportes fundamentales de Juan Damasceno se da en el terreno de la percepción y la apreciación del "arte" en un sentido incluso más extensivo que el de la "restringida iconografía" visual: "Porque a través de los sentidos (es decir todos los sentidos) se forma determinada imagen en la parte frontal del encéfalo y desde allí se transmite a la función del juicio y es almacenada en la memoria” (PG, 1281 C). Por consiguiente, la imagen constituye la forma básica de la percepción desde el punto de vista "psicológico" (o lo que se atenga a este término a la sazón) del ser humano y es esto en última instancia, lo que justificaría también la existencia de todo arte representativo en todo soporte, ya sea literario, visual o sonoro, en los tres casos se trata en efecto de un "icono".
Siguiendo este cuarto argumento filosófico es que basa sus opiniones sobre los iconos otro célebre iconófilo, Teodoro el Estudita (759-826 d. C.), en su texto Discursos Refutatorios en contra Iconoclastas: "Porque no se trata de una misma cosa el arquetipo y el icono, puesto que lo uno es la verdad, lo otro una sombra" (PG, 99: 44). Es posible apreciar la conexión existente entre el argumento platónico, la célebre "alegoría de la caverna", a partir del cual puede deducirse que la "verdad" constituye el ente representado en sí mismo, es decir la sustancia del ente, en tanto que esta "sombra" consiste en la revelación o expresión de esta "verdad". En este sentido ańade que "De todo lo representado no se trata de su naturaleza, sino de la hipóstasis" (PG, 99: $461 \mathrm{C})$, es decir de la "persona" representada o "retratada", cuestión que tiene que ver con la posibilidad de representar a Cristo, es decir, a la entidad divina después de la unión con la naturaleza humana. No obstante, la obra de arte no puede reflejar, o mejor dicho "imitar" nunca la naturaleza del representado, teniendo en cuenta que la obra permanece siendo obra, el ente, ente. Sin embargo, la naturaleza del representado se experimenta a través de la obra de arte, gracias a su carácter alegórico y simbólico y el mencionado "principio de la referencialidad".

Por último está aquello de que “(...) una cosa es el sello y otra la marca. Sin embargo, antes de sellar, la marca se encontraba en el sello, aunque este no estuviese actuando, sin estar impreso en ninguna materia" (Teodoro el Estudita, PG, 99: 432). Por lo que se trata de "arte" no solo como resultado de la dialéctica saber-creación, sino como una fisonomía característica del ente. La "vocación" del artista consiste, entonces, en el descubrimiento y revelación posterior de esta determinada fisonomía, diríamos "artística", la cual es inherente al ente por naturaleza ${ }^{9}$ 
e imprescindible en la "experiencia de desocultamiento", es decir la verdad o "aletheia".

Otro teólogo de Bizancio, igualmente digno de mención, es Fotios el Grande (820-893 d. C), cuyas ideas estéticas presuponen la cuestión de la "recapitulación de todo en Cristo". ${ }^{10}$ Esto significa que su estética se extiende también más allá de las disciplinas del arte eclesiástico, al arte en general, específicamente pagano, y a la naturaleza, creación de Dios. En su obra Myriobiblos (PG, 103), claramente influida por la filosofía clásica y especialmente por Aristóteles, aparecen cuatro categorías estéticas dedicadas a la belleza (Theodórou, 1995: 182):

1) La "belleza clásica", el ideal griego de la armonía y la simetría, que obviamente se manifiesta en la arquitectura y la escultura grecorromanas.

2) El "charíen" sustantivación del

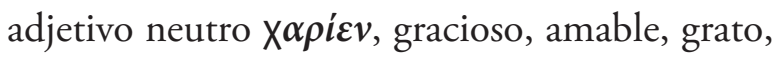
elegante, agradable, para Fotios, la belleza que reside en el movimiento de los elementos; por ejemplo, desde los rayos del sol, las olas del mar, el resplandor del oro, los movimientos de las golondrinas, cisnes y delfines, hasta los cantos de ruiseñores y los colores de los peces.

3) La "belleza elevada o superior", que se encuentra generalmente entre los entes celestiales como las estrellas, los fenómenos naturales celestes como el resplandor, el relámpago y el sonido de las tormentas. En esta categoría también se incluyen los paisajes de grandes dimensiones y la actividad de los volcanes.

4) La "belleza de lo cómico y trágico, donde puede apreciarse la influencia de la Poética de Aristóteles. Fotios entiende el carácter pedagógico del arte, como resultado del enfrentamiento del mal y la muerte por el ser humano. Esto puede percibirse sobre todo en el caso de la tragedia griega, una pedagogía antropológica que persigue la restauración ontológica del hombre.

Todas estas categorías se derivan ya sea del elemento natural o del objeto artificial, presuponiendo determinado estado de "pureza" o "catarsis" a la hora de experimentar la "belleza". Esto último vale tanto para el creador ( $\pi$ oı $\eta \tau \eta \dot{\varsigma} /$ poeta), como el espectador o "participante" de la obra, en tanto que la sustancia o esencia de la "belleza" constituye la "verdad", elemento que queda manifestado expresamente en su obra Amfilochia, refiriéndose a la sabiduría del discurso artístico:

(...) cuando con prudencia se manifiesta, de modo asequible enseña, al más alto grado educa, por sí sola persuade, de manera inteligible despliega la naturaleza de las cosas a través de la asociación de significados ${ }^{11}$, y si necesitara mostrar mucho más que esto, místicamente, de manera absoluta, cual si se tratase de una iniciación religiosa, descubre la «verdad» de los fenómenos ocultos. (Fotios Magno, PG, 101: 584)

Pero estas teologías del arte no se encuentran completas, sino en un largo proceso de perfeccionamiento que, según nuestra opinión, se vería culminado con la teoría de las “energías divinas" de Gregorio Palamás (12961359). Esto es que el ser humano experimenta de Dios, solamente sus "energías divinas increadas", al tiempo que su esencia o sustancia divina permanece inaccesible. Al respecto, el teólogo ruso Vladimir Lossky (1903-1958) señalaría que “(...) la veneración de los iconos, constituye de alguna manera el comienzo de la contemplación de Dios" (Lossky, 2004: 219). No obstante, resulta curioso que ninguna iconología 
bizantina intentó formular esta correlación entre el arte y la experiencia de la Luz Increada, elemento inherente a toda práctica ascética cristiana y por eso «(...) cuando los hesicastas bizantinos se refieren al icono, no relacionan con la práctica espiritual, ni la veneración, ni la creación de este" (Uspensky, 1993: 308). Cosa que no significa que la relación entre el arte y la experiencia mística resulte inexistente o que se haya improvisado en retrospectiva. Parece que este vacío en la literatura se debe, en primer lugar, al hecho de que la Iglesia de Oriente estuvo más interesada en la experiencia real, es decir, en el resultado de esta forma de conocimiento de la "verdad" de Dios, el arte, más que en el medio en sí mismo. En segundo lugar, porque la teología oriental en los últimos siglos tanto debido a la influencia de la Ilustración europea, como por razones de rivalidad confesional ante Occidente, no profundizó nunca en estas cuestiones.

El pensamiento teológico ruso, a diferencia del greco-bizantino presentaría un gran interés por la cuestión del arte religioso. En Rusia ha existido una gran producción de tratados sobre iconografía desde diferentes perspectivas, tanto teóricas, como prácticas, teológicas y técnicas, relativas a la estructura y el uso de los medios de producción pictóricos. El teólogo e iconógrafo ruso Leonidas Uspensky (1902-1987) se refiere a una importante obra, titulada Mensaje a un Iconógrafo así como el Sinodo de los 100 Capitulos (Stonglav) en 1547, donde se redactó una especie de "canon para la creación iconográfica”.

El caso de la teología del siglo XX, sobre todo a partir de los años 50 y 60, resulta también de interés para esta investigación. Aquí existe una notable regeneración, tanto de la teología patrística ya mencionada, como de la literatura rusa dedicada al arte iconográfico, cuestión que se debe no solo a la influencia del texto de la Filocalia, sino también al Concilio Vaticano II. Durante este período actúa una generación de teólogos rusos, la mayoría citados en el presente trabajo, conocida como Generación de la Diáspora Rusa, la cual marcó de una forma muy característica la teología contemporánea, especialmente el estudio del arte cristiano. ${ }^{12}$

"Tanto desde un punto de vista artístico, como espiritual, el icono constituye el descubrimiento más importante del siglo XX” (Uspensky, 1993: 589). Esta afirmación de Leonidas Uspensky (1902-1987), un tanto "romántica", revela, en esencia, que el descubrimiento o re-descubrimiento del icono por el pensamiento occidental, introduce en la modernidad un nuevo concepto, una nueva perspectiva en el terreno de la filosofía del arte que no puede pasar desapercibida. En principio, es importante entender que casi de la misma manera con que Heidegger pretende una reestructuración crítica de la comprensión contemporánea de la "belleza clásica", partiendo de que no se puede abarcar completamente desde la ciencia estética, así también la teología oriental del arte estudia la obra de arte y su "comprensión", como una experiencia que trasciende los sentidos, la "aisthesis" propiamente dicha. A esto último debemos aducir en este contexto, la imposibilidad de justificar la existencia del arte sólo a partir del hecho de que el ser humano constituye un ente sensible. Por lo tanto, en el arte eclesiástico oriental no se pretende que el hombre experimente la realidad tal y como es o como aparece ante sus ojos, sino lo que hay detrás de ella: "El arte «des-fenomeniza» la realidad tal y como es, y el mundo entero se abre al misterio. Allí termina la estética" (Evdokimov, 1982: 26).

Esta "des-fenomenización” constituye una faceta de la práctica ascética, de la ética 
y metafísica cristiana, cuyos parámetros permanecen vigentes en la teología oriental, bizantina y meta-bizantina. Es por esto último que “(...) la belleza no es sólo una realidad ética, sino también metafísica", advierte Pavel Evdokimov (1982: 27), teniendo en cuenta que la "belleza", esta fisonomía específica del ente, según Heidegger este modo de existencia de la "verdad", no permanece en la obra de arte como un mero "espectáculo", sino como una experiencia trascendente, o como hemos citado anteriormente, una "des-fenomenización del ente". O lo que es lo mismo, que "(...) el resplandor (lo físico) es inseparable de la verdad (lo metafísico)" (1982: 28).

Este "resplandor" resulta una peculiaridad de la "verdad", es decir de Cristo. Sin embargo, la concepción de la "verdad" según la doctrina cristiana no consiste en la experiencia de algo abstracto, sino en la participación en la persona del "Theanthropos", y por esto escribe el teólogo: “(...) este resplandor no existe en lo abstracto. En el nivel de su plenitud, demanda una personificación, pide ser en-hipóstato, y Cristo responde declarando: Yo soy la Verdad" (1982: 28). El teólogo concluye que "la belleza cristiana” es el mismo Cristo, la belleza del icono del Padre (Cristo) que se manifiesta por el Espíritu Santo, y que con razón puede ser llamado también "Espíritu de la Belleza".

Teniendo en cuenta que la "belleza" de la "verdad" resulta trascendente de manera absoluta, en cada caso difiere esencialmente de las cualidades materiales de cualquier ente, pero se sirve en su revelación o estetización, de la propia realidad natural e inmanente: "(...) se da en sí misma o a través de las fórmulas -tiposde este mundo" (Evdokimov, 1982: 133). Entre todas estas fórmulas o medios convencionales de expresión de la belleza, el más privilegiado resulta sin dudas, la obra de arte, que por un lado constituye un ente, material y sensible, pero, por otro, le ha sido ańadido otro elemento de índole metafísica, la "alegoría" y el "símbolo" (Heidegger, 1992: 40-41). Es precisamente en este elemento donde se encuentra la posibilidad de la obra de arte de mostrar la "verdad o belleza trascendental” y por eso “(...) un símbolo, dentro del espíritu de los Padres y según la tradición litúrgica, abarca en sí mismo la presencia de aquello que simboliza", dice Evdokimov (1982: 133). Lo que se constituye básicamente, en aquella antigua teo-filosofía de la presencia de san Juan Damasceno, mediante la cual comenzábamos el análisis presente.

\section{El discurso estético bizantino}

permanece todavía inexplorado por la cultura contemporánea. En un momento en que el arte atraviesa una crisis de sentido, una incertidumbre en lo que respecta a su porqué y para qué, parece conveniente dialogar un poco con este pasado, teniendo en cuenta que sigue vivo detrás de toda creación artística, donde todavía es posible experimentar el resplandor de la verdad del "Logos”, la persona del “Theánthropos”. De esta manera, podrían cumplirse quizás las palabras del poeta y teólogo, en un contexto mucho más amplio y constructivo que el de la propia cristiandad:

Sí, Soberano, venero todo lo que es tuyo y con deseo ardiente abrazo tu naturaleza divina, tu fuerza, tu bondad, tu magnificencia, tu condescendencia, tu encarnación, tu carne. Y del mismo modo que siento temor de tocar el hierro incandescente, no por causa de su naturaleza, sino como consecuencia del fuego unido a él, así venero tu carne, no por causa de su naturaleza, sino como consecuencia de la divinidad 
(naturaleza divina) hipostáticamente unida a ella". (Juan Damasceno, PG, 94: $1281 \mathrm{C})$

\section{Notas:}

1 Esto es conforme a la acepción griega de la palabra $\tau \dot{\varepsilon} \chi v \eta /$ téchni, saber, maestría, conocimiento de determinada regla o canon. En este caso del canon representativo del icono bizantino o meta-bizantino, que permanece vigente todavía en el cristianismo oriental. Por otra parte, teniendo en cuenta también que todavía se trata de un proceso "kalokagáthiko", es decir que resulta imposible distinguir plenamente entre la utilidad y la belleza del objeto, lo "artesanal" y lo "artístico", lo "religioso" y "estético", salvando la terminología empleada de cualquier acepción posterior.

2 El propio Hans Belting realiza esta distinción en su texto Imagen y Culto... publicado originalmente en 1990: "Por ello, adelantamos que en la presente historia se entiende por imagen el retrato personal, la imago, que normalmente representaba a una persona y era tratada, por esa misma razón, como una persona, convirtiéndose así en un objeto privilegiado de la práctica religiosa. En este contexto religioso, se veneraba la imagen como objeto de culto (...)" (2009: 5).

3 En este sentido no nos parece completamente acertado el criterio de Hans Belting, primeramente porque da por sentado que el icono en la historia ha funcionado más como un órgano "ideológico-político-institucional", que una teología en soporte artístico: "Los teólogos han intentado una y otra vez arrancar su poder a las imágenes materiales cuando éstas amenazaban con ganar demasiado poder en la Iglesia. Las imágenes pasaban a ser rechazadas tan pronto como comenzaban a atraer más público que las instituciones mismas y a actuar por su parte en nombre de Dios" (2009:9). Debemos aclarar que muchos "teólogos" también dieron su vida, esto considerado como martirio real, en virtud de sus actitudes "iconófilas"; además de que la mayoría de las contiendas iconoclastas no brotaron espontáneamente de una institución eclesiástica "monolítica", sino que fueron impulsadas por jerarquías seculares y religiosas (no por "teólogos") que en posesión absoluta del poder se encontraban influidos por un ámbito exo-eclesiástico, a nivel cultural y confesional, como es el caso del emperador León III el Isaurio (c. 680-741), nacido en Siria dentro de un contexto cultural iconoclasta.

4 Los textos en griego en el original han sido traducidos directamente por el autor de este ensayo, en ausencia de ediciones en español.

5 A lo que debemos aducir que "icono" no consiste plenamente ni en "símbolo" ni "alegoría", pero, hasta donde sabemos, en el contexto bizantino y meta-bizantino sí tiene que ser siempre "simbólico" y "alegórico".

6 Utilizando aquí las definiciones heideggerianas que a nuestro entender no constituyen tanto un reflejo de la estética y la teoría del arte moderna, sino más bien una hermenéutica, un análisis profundo de la "estética" y la "teoría del arte" de la Grecia antigua. Elemento que como veremos se mantiene en una estrecha relación con la cultura conocida como "bizantina", la cual se pretende erróneamente englobar dentro de la totalidad de la Edad Media, así como separar de la cultura griega clásica. No obstante este punto se encuentra todavía abierto a distintas apreciaciones. Por ejemplo, Belting considera que "la historia común de la imagen de Oriente y Occidente llegó lentamente a su final hacia el año 1200". Elemento que a nuestro parecer resulta contradictorio, considerando que asevera también que "ya en el siglo XI Bizancio poseía una estética filosófica de la imagen, algo que Occidente no lograría hasta el Renacimiento" (1990: 6). No obstante se trata de una perspectiva muy personal, en el orden historiográfico y de la teoría del arte y la imagen, lo cual no se contrapone al objetivo principal del estudio presente, con un corte más estético-teológico.

7 En clave heideggeriana algo así como "lo que tiene de cosa la cosa", dando por sentado que la obra de "arte" se trata en primer lugar de una cosa. 
8 El origen de esta problemática puede detectarse desde muy temprano, por ejemplo en las traducciones del Antiguo Testamento, y específicamente del mandamiento "iconoclasta" en Ex 20:4-5, que se repite también en Dt 5:

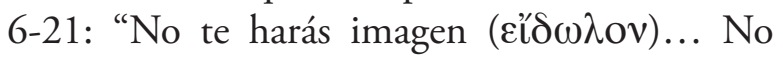

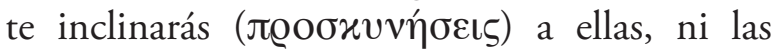

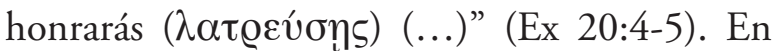
este caso tal y como es traducido por la edición Reina Valera, aunque las palabras destacadas tienen un sinnúmero de acepciones en el griego helenístico. En primer lugar, el término $\varepsilon i ð \omega \lambda$ ov/eídolon, que se utiliza con un sentido peyorativo y designa principalmente la estatua dedicada a "falsas deidades" (Bambiniotis, 1995: 556). Nótese que el traductor, sin duda un judío helenístico, se cuida muy bien de utilizar la palabra cixúv/eikón pese a que ambos términos bien pudieran emplearse como sinónimos en otros contextos y comparten una raíz etimológica muy cercana, en el primero عídos/eídos, "aspecto" y en el segundo ěoı $\alpha /$ éoika, "igualar, asemejar". El propio Heidegger hace notar esta relación en su texto La doctrina de Platón acerca de la verdad, donde hace referencia tanto a cl'os $/$

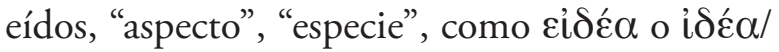
idea, esto es "imagen", "reflejo" y posteriormente "idea" propiamente dicha (2007). Lo importante aquí es que existe una suspicacia a la hora de emplear un término o el otro (ídolo o ícono), a tal punto que el célebre pasaje del Génesis en su traducción helenística se decanta por la forma no peyorativa: "Hagamos al hombre a nuestra imagen (cixóva/eikóna), conforme a nuestra semejanza (...) Y creó Dios al hombre a su imagen (عixóva/eikóna), a imagen de Dios lo creó" (Gn 1: 26-27). Elemento que a nuestro juicio abre el camino posterior a las reflexiones de Juan Damasceno en referencia al uso de los términos y con respecto al citado "mandamiento iconoclasta" en el uso de los verbos $\pi \varrho 0 \sigma x v v \omega /$ proskynó, "inclinarse", "venerar" y $\lambda \alpha \tau \varrho \varepsilon v ́ \omega /$ latrévo, "adorar". Acciones que se encuentran prohibidas "terminantemente" en el A. Testamento, pero que el Damasceno resignifica a partir de la explicación que se da más arriba.

9 A similares conclusiones conducen también otras teorías más contemporáneas, como las de Heidegger y Pavel Evdokimov en El Origen de la
Obra de Arte (Arte y Poesía, 1992) y H Téchni tis Eikónas. Theología tis Oraiótitas/El Arte del Icono. Teología de la Belleza (1982), respectivamente.

10 "(...) dándonos a conocer el misterio de su voluntad, según su beneplácito, el cual se había propuesto en sí mismo; que en la dispensación del cumplimiento de los tiempos, había de reunir ( $\dot{v} \alpha x \varepsilon \phi \alpha \lambda \alpha \iota \omega ́ \sigma \alpha \sigma \theta \alpha \iota:$ recapitular) todas las cosas en Cristo, así las que están en el cielo, como las que están en la tierra, aun en Él. (Ef, 1: 9-10)

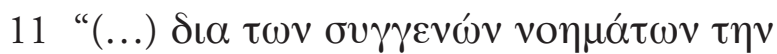

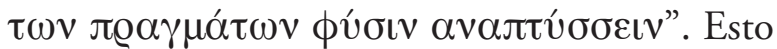
es, "simbólicamente", en virtud de la acepción referida anteriormente.

12 En este estudio se considera que existe una cohesión absoluta desde el punto de vista teológico entre la iconofilía bizantina y la meta-bizantina y que esta última no constituye meramente "la visión romántica" de un puñado nostálgico de "amantes de los iconos" (Belting, 2009: 6), sino con mayor propiedad de una teología consecuente en el sentido más contemporáneo de la palabra, que puede confirmarse por aquellos que en definitiva mantienen viva la teología de la imagen dentro de la praxis religiosa. El fenómeno de la Teología de la Diáspora Rusa también ha sido estudiado por el sociólogo y teólogo griego contemporáneo Ioánnis Petrou, quien asegura en sus conferencias que ha constituido en buena medida una forma de auto-afirmación del exiliado ruso, en este caso de su condición cultural e identidad religiosa. En este sentido, también debemos considerar la opinión de otro contemporáneo, eslavólogo y teólogo griego también, Elías Evangelou, quien considera en sus lecciones que ya sea romántica o una estrategia de inmigrante, esta corriente permaneció trabajando sobre la base de la misma teología ortodoxa sin llegar a un producto esencialmente distinto, sino "enriquecido" en buena medida.

\section{Bibliografía:}

Bambiniotis, G. (1995). Lexikó tis Néas Ellinikis Glóssas. Athína: Kentro Lexikologías. 
Belting, H. (1990). Imagen y Culto. Una historia de la imagen anterior a la edad del arte. Madrid: Akal.

Bulgakov, S. (1988). The Orthodox Church, New York: St. Vladimir's Seminary Press.

Evdokimov, P. (1982). I Téchni tis Eikónas. Theologia tis Oraiótitas, Thessaloníki: Pournarás.

Florovsky, G. (2007). Oi Byzantinoi Patéres tou Éktou, Ébdomou kai Ógdoou Aióna, Thessaloníki: Pournarás.

Gombrich. E. H. (2011). La Historia del Arte. London: Phaidon.

Heidegger, M. (1992). Arte y Poesía, Buenos Aires: Fondo de Cultura Económico. (2007). La doctrina de Platón acerca de la verdad. Eikasia: Revista de filosofía, $N^{o}$. 12. pp. 261-284.

Kaimakis, D. (2007). Thémata Palaiodiathikikis Theologias, Thessaloníki: Banias.

Lossky, V. (2004). I Théa tou Theoú, Prébeza: I. M. Nikopóleos.

Matsoukas, N. (2010). Dogmatikí kai Symboliki Theología B', Thessaloníki: Pournarás.

Migne, J. P. (ed.) (1857). Patrologiae Graecae (PG). París: Bibliothecae Cleri Universae.

Ouspensky, L. (1993). I Theologia tis Eikónas stin Orthódoxi Ekklisía, Athína: Armós.

Theodórou, E. D. (1995). "I Aisthitikí tou Fotíou tou Megálou” en Praktiká IE' Theologikoú Synedriou "Mégas Fótios», Thessaloníki: Ierás Mitropóleos Thessaloníkis.

Yfantis, P. Ar. (2010). Klisi, Poreía kai Metochi, Athina: Armós. 